\title{
IMUNOSSUPRESSÃO DE OPERÁRIAS DA FORMIGA- CORTADEIRA Atta sexdens SOB EFEITO DO ZINCO
}

Iunosuppression of the leaf-cutting ant Atta sexdens under the effect of zinc

Inmunosupresión de la hormiga cortadora de hojas Atta sexdens bajo el efecto del zinc

\section{Amanda Caroline Teles Tenório ${ }^{1}$, Cynthia Lhourrana Santos Silva ${ }^{2}$, Danival José de Souza*2}

${ }^{1}$ Curso de Engenharia de Bioprocessos e Biotecnologia, Universidade Federal do Tocantins, Gurupi, Brasil.

${ }^{2}$ Laboratório de Simbiose Insetos Microrganismos, Programa de Pós-graduação em Produção Vegetal,

Universidade Federal do Tocantins, Gurupi, Brasil.

*Correspondência: Laboratório de Simbiose Insetos Microrganismos, Programa de Pós-graduação em Produção Vegetal, Rua Badejós, Jardim Sevilha, Gurupi, Tocantins, Brasil.CEP:77.410-530.e-mail danival@uft.edu.br.

\section{RESUMO}

As formigas-cortadeiras têm grande importância econômica, já que podem cortar e utilizar ampla diversidade de espécies vegetais cultivadas pelo homem. Este trabalho estudou os efeitos do zinco nas formas de cloreto e sulfato sobre o sistema imune da formiga-cortadeira Atta sexdens. Os experimentos consistiram na imersão das formigas em soluções de sulfato de zinco $\left(\mathrm{ZnSO}_{4}\right)$ e cloreto de zinco $\left(\mathrm{ZnCl}_{2}\right)$. Para a contagem total de hemócitos, foi feita a retirada da hemolinfa, e a concentração de hemócitos foi submetida à análise de variância pelo teste $\mathrm{F}(\mathrm{p} \leq 0,05)$ seguida por regressão polinomial $(\mathrm{p} \leq 0,05)$. A encapsulação foi medida por meio do implante de um monofilamento de nylon, um antígeno inerte, nas operárias e taxa média de encapsulação dos diferentes tratamentos foi submetida à análise da variância pelo teste $\mathrm{F}(\mathrm{p} \leq 0,05)$ seguido pelo teste Scott-Knott a 5\% de probabilidade. As diferentes formas de sais de zinco diminuíram significativamente a concentração de hemócitos das operárias. A taxa de encapsulação não apresentou diferenças significativas entre os tratamentos. $\mathrm{O}$ sulfato de zinco apresentou-se mais eficiente na redução dos hemócitos em relação ao cloreto de zinco, pois reduziram significativamente a imunidade desses insetos. Palavras-chave: Sulfato de zinco, Cloreto de zinco, Imunidade.

\section{ABSTRACT}

The leaf-cutting ants are of great economic importance because they can cut a wide variety of vegetable crops. This work studied the effects of the zinc (chloride and sulfate) on the immunity of the leaf-cutting ant Atta sexdens. The experiments consisted of immersing ant workers in solutions of zinc sulfate (ZnSO4) and zinc chloride (ZnCl2). Hemocyte count was performed by removal of hemolymph and counting the concentration of hemocytes, comparing the mean number by variance test $F(p \leq 0.05)$ followed by polynomial regression $(p \leq 0.05)$. The encapsulation was evaluated by the implantation of nylon monofilament, an inert antigen, in the workers, and measuring the encapsulation rate. The values of different treatments were submitted to variance analysis and compared by the Scott-Knott test at 5\% probability. The different forms of zinc salts significantly decreased the concentration of hemocytes of the ant workers. Encapsulation rate did not present significant differences between the treatments. The zinc sulfate seems to be more effective in reducing the hemocytes about the zinc chloride, thus significantly reducing the immunity of these insects.

Keywords: Zinc sulfate, zinc chloride, immunity. 
Las hormigas cortadoras de hojas son de gran importancia económica porque pueden cortar una gran variedad de cultivos agrícolas. Este trabajo estudió los efectos del zinc (cloruro y sulfato) sobre la inmunidad de la hormiga cortadora de hojas Atta sexdens. Los experimentos consistieron en sumergir las hormigas en soluciones de sulfato de zinc ( $\mathrm{ZnSO4}$ ) o cloruro de zinc ( $\mathrm{ZnCl2)}$. Mediante la colección de la hemolinfa se realizó el recuento de hemocitos y fue usado la prueba $F$ (igualdad de varianzas) para comparar los promedios de los tratamientos $F(p \leq 0.05)$ seguida de regresión polinómica $(p \leq 0.05)$. Se evaluó la encapsulación mediante la implantación de monofilamento de nylon, un antígeno inerte, en las obreras, y midiendo la tasa de encapsulación. Los valores de los diferentes tratamientos se compararon mediante pruebas estadísticas. Los valores de los diferentes tratamientos se sometieron a análisis de varianza y se compararon mediante la prueba de Scott \& Knott al 5\% de probabilidades. Las diferentes formas de sales de zinc disminuyeron significativamente la concentración de hemocitos de las obreras de hormigas. La tasa de encapsulación no presentó diferencias significativas entre los tratamientos. El sulfato de zinc parece ser más eficaz para reducir los hemocitos en comparación con el cloruro de zinc, lo que reduce significativamente la inmunidad de estos insectos.

Descriptores: Sulfato de zinc, cloruro de zinc, inmunidad.

\section{INTRODUÇÃO}

As formigas-cortadeiras destacam-se como formigas de importância econômica, pois são nocivas ao sistema agrossilvipastoril, já que podem cortar e utilizar ampla diversidade de espécies vegetais cultivadas pelo homem (DELLA LUCIA, 2011). Devido ao seu comportamento eussocial, as formigascortadeiras possuem estratégias que dificultam seu combate, além de possuírem alta capacidade de reconhecimento de substâncias químicas tóxicas que podem prejudicar o desenvolvimento de seu fungo simbionte ou mesmo as operárias forrageadoras (DELLA LUCIA, 2011; DELLA LUCIA et al., 2014).

Dentre os fatores que dificultam o controle de formigas-cortadeiras, destaca-se o seu sistema imune inato que, assim como o de outros insetos, está intimamente associado aos constituintes celulares da hemolinfa (hemócitos) e líquidos (plasma), onde os fatores humorais são dissolvidos (de SOUZA et al., 2013). Siddiqui e Al-Khalifa (2014) destacam que os hemócitos possuem atividade fagocitária, sendo possível observar tal mecanismo por meio da injeção de partículas estranhas, como esporos fúngicos e nanquim, na hemocele de insetos. Outro mecanismo de defesa celular observado nesses insetos, e nos invertebrados em geral, é a encapsulação de corpos estranhos, geralmente maiores que aqueles englobados pela fagocitose (RATCLIFFE e ROWLEY, 1979). Não se limitando a isso, esse mecanismo também desempenha um papel na defesa contra vírus (WASHBURN et al., 1996), por meio de uma melanização visível da cápsula formada (RATCLIFFE et al., 1985). A reação de encapsulamento seguida da melanização tem sido utilizada para avaliar a imunidade de formigas através da inserção de um implante que correlaciona seu grau de escuridão com a imunidade desses organismos (SORVARI et al., 2008; de SOUZA et al., 2013; COUCEIRO et al., 2016).

Alguns elementos químicos podem interferir na resposta imune de insetos. Por exemplo, o metaloide arsênico ou os metais cádmio e chumbo afetaram o sistema imune da formiga Formica aquilona Yarrow (SORVARI et al., 2007). Além disso, metais podem interferir na simbiose das formigas-cortadeiras de outras maneiras. Estudos recentes com Atta sexdens relatam que altas doses de cloreto e sulfato de zinco inibem o desenvolvimento do seu fungo simbionte $-L$. gongylophorus - e afeta significativamente seu sistema imune (SILVA, 2016).

O Zinco ( $\mathrm{Zn}$ ) é um importante micronutriente que atua no controle hormonal a partir da síntese do triptofano, precursor do ácido indolacético (AIA) 
responsável pelo aumento de volume celular (MARSCHNER, 1995). O solo do cerrado possui deficiência deste micronutriente (GALRÃO, 1994; RODRIGUES et al., 2012) fator limitante ao desenvolvimento das pastagens na Região do Cerrado (VENDRAME et al., 2007) com destaque mais recente para a cultura de Eucalyptus (RODRIGUES et al., 2012). Aqui, objetivou-se avaliar o efeito do zinco, nas formas cloreto e sulfato de zinco, no sistema imune da formiga-cortadeira A. sexdens, amplamente distribuída no Brasil e com alta abundância de ninhos na região de Gurupi, sul do Tocantins.

\section{MATERIAIS E MÉTODOS}

Operárias forrageadoras de A. sexdens foram coletadas na Fazenda Experimental da Universidade Federal do Tocantins, Campus Gurupi (Coordenadas Geográficas -11.772395, -49.044173). Foram demarcadas ao acaso 4 colônias, das quais retiraram-se operárias com largura da cápsula cefálica em torno de 2,0-2,5 mm. As operárias coletadas foram levadas ao Laboratório de Simbioses Insetos Microrganismos da Universidade Federal do Tocantins, Campus de Gurupi, onde foram imersas em soluções de sais de zinco (sulfato de zinco e cloreto de zinco) por 20 segundos. Utilizou-se as seguintes concentrações de $\mathrm{ZnSO}_{4}: 0,15 ; 0,25 ; 0,50 ; 1,50 ; 2,50$ e $5,00 \mathrm{~g} \mathrm{~L}^{-1}$, e as seguintes concentrações de $\mathrm{ZnCl}_{2}: 0,13 ; 0,21 ; 0,42$; 1,$26 ; 2,1 ; 4,2 \mathrm{~g} \mathrm{~L}^{-1}$, para corresponder às doses equivalentes de $\mathrm{Zn}$, em que grupos de 20 operárias foram destinados a uma das concentrações dos sais de zinco. Posteriormente, as formigas imersas nas soluções foram colocadas sobre folhas de papel filtro, previamente esterilizado, para retirar o excesso de solução e colocadas em tubos de ensaio de vidro com algodão umedecido com água destilada esterilizada, ficando acondicionadas durante 24 ou 48 horas em temperatura de $25^{\circ} \mathrm{C} \pm 1{ }^{\circ} \mathrm{C}, 75 \% \pm 5 \% \mathrm{U}$. R. O mesmo processo foi aplicado para as operárias do grupo controle, entretanto, essas foram imersas em água destilada esterilizada apenas. Outro grupo controle foi constituído por operárias não imersas em água.

Após o período de tempo de 24 ou 48 horas, foi analisado cada grupo de 20 operárias imersas nas respectivas soluções de sais de zinco, em que 10 operárias foram destinadas a análises no período correspondente à 24 horas e 10 operárias a um período de 48 horas. Retirou-se $1 \mu \mathrm{L}$ de hemolinfa da região occipital da cabeça de cada operária, com auxílio de tubo microcapilar Sigma-Aldrich de $1 \mathrm{~mm}^{2}$, dispondoa em um tubo eppendorf contendo $4 \mu \mathrm{L}$ de solução anticoagulante (SAI) (LEONARD et al., 1985). A mistura foi ressuspendida com auxílio de uma pipeta. A contagem total de hemócitos foi realizada imediatamente após a coleta, utilizando-se câmara de Neubauer com auxílio de um microscópio óptico de luz, em que $0,5 \mu \mathrm{L}$ de corante Giemsa foi adicionado à mistura para auxiliar na visualização dos hemócitos. Funcionalmente, os hemócitos são geralmente unidades de defesa celular em insetos e são parcialmente responsáveis por seu sistema imunológico (RIBEIRO e BREHÉLIN 2006; WOOD e JACINTO 2007).

A partir da equação 1, pôde-se obter o número estimado de hemócitos/ $\mu \mathrm{L}$ :

$\mathrm{N}=\left(\mathrm{n}^{\circ}\right.$ médio de hemócitos contados em C) x $(2,5 \mathrm{x}$ $\left.10^{2}\right) \times \mathrm{D}$

Em que $\mathrm{N}$ corresponde ao número de hemócitos/ $\mu \mathrm{L}, \mathrm{C}$ representa o quadrante da Câmara de Neubauer utilizado na contagem e $\mathrm{D}$ o fator de diluição utilizado correspondente a 5. Os dados foram submetidos à análise da variância pelo teste $\mathrm{F}$ (p $\leq$ 0,05). Para o fator quantitativo (doses de zinco), as 
médias foram ajustadas por equações de regressão polinomial $(\mathrm{p} \leq 0,05)$ usando-se o programa SISVAR (FERREIRA, 2011).

Os mesmos critérios morfológicos para a escolha das operárias, local de coleta e imersão em sais de zinco descritos na metodologia de imersão em Sulfato de Zinco $\left(\mathrm{ZnSO}_{4}\right)$ e Cloreto de Zinco $\left(\mathrm{ZnCl}_{2}\right)$, foram adotados. A resposta imune das operárias foi medida através da inserção de um antígeno inerte de 0,1 $\mathrm{mm}$ de diâmetro de um monofilamento de nylon estéril, cortado com auxílio da lupa Leica S8AP0 e bisturi estéril, em seguida inseridos no tórax de cada formiga com auxílio de pinça cirúrgica, entre o segundo e terceiro pares de perna (de SOUZA et al., 2013). Após a introdução do antígeno, as operárias foram colocadas individualmente em tubos de ensaio de vidro, contendo algodão umedecido com água destilada esterilizada. Os tubos foram mantidos em uma sala climatizada a $25{ }^{\circ} \mathrm{C}$ $\pm 1{ }^{\circ} \mathrm{C}, 75 \% \pm 5 \%$ U.R.

As inserções foram feitas de forma que cada grupo de 20 operárias, imersas em diferentes doses de sais de zinco, foram submetidas ao implante do monofilamento de nylon separadamente, sendo que 10 operárias foram submetidas ao implante no tempo zero e tiveram seus implantes analisados após 24 horas e 10 operárias foram submetidas ao implante 24 horas após a imersão na sua respectiva dose de sal de zinco e tiveram seus implantes analisados após 48 horas. $\mathrm{O}$ mesmo processo foi aplicado para as operárias do grupo controle, imersas em água destilada esterilizada e não imersas em água.

O monofilamento de nylon foi removido com auxílio de pinça cirúrgica, disposto em lâmina de vidro, em seguida, coberto com D-limoneno para auxiliar na fixação e recoberto com lamínula. Estabeleceu-se o mesmo procedimento para a remoção do monofilamento de nylon em ambos os tempos (após 24 horas e após 48 horas). Após a remoção, o antígeno foi examinado sob um microscópio de luz Leica DM500 e fotografado usando o software do microscópio Leica EZ V3.0. O valor cinzento médio de todo o implante indicando a taxa de encapsulação foi medido utilizando o software Corel-PHOTO-PAINT 2018, em que, o valor de cinza de fundo foi subtraído para corrigir os valores cinzentos dos implantes. Os tratamentos foram submetidos à análise da variância pelo teste $\mathrm{F}(\mathrm{p} \leq 0,05)$ seguido pelo teste Scott-Knott a 5\% de probabilidade utilizando o programa SISVAR.

\section{RESULTADOS E DISCUSSÃO}

Houve interação significativa entre quantidade de hemócitos/ $\mu \mathrm{L}$ e as diferentes doses de sais de zinco $(\mathrm{p} \leq 0,05)$, exceto, para as doses relacionadas a $\mathrm{ZnSO}_{4}$ durante o período de 24 horas, em que, as formigas da espécie Atta sexdens, submeteram-se à imersão neste composto $\left(\mathrm{ZnSO}_{4}\right)$ em diferentes concentrações, confere-se então a estes efeitos de aumento e/ou diminuição de hemócitos ao acaso, fato contrário ao que observado por Silva (2016), em que formigas da mesma espécie submeteram-se às mesmas concentrações de $\mathrm{ZnSO}_{4}$, em um tempo de 24 horas. Essa variação da resposta imune ilustra a sua complexidade e a necessidade de maiores estudos para compreendê-la. Qamar (1990) e Qamar e Jamal (2009) estudaram os efeitos comparativos das concentrações subletais de diclorodifeniltricloroetano (DDT) (5000, 2500, 1250, 625 e 312,5 ppm), Cythion-a 90\% malathion (80, 60, 40, 20 e 10 ppm) e Furadan (10, 8, 6, 4 e 2 ppm), após a aplicação tópica de cada concentração de inseticida verificaram que em ninfas de Dysdercus cingulatus o número total de hemócitos não variava em relação ao controle.

Observou-se também que os grupos controle (operárias imersas em água destilada e não imersas em 
água) não apresentaram variações entre si. A variação foi observada apenas em relação ao tempo das análises (24 e 48 horas), optando-se então por realizar médias entre os controles de acordo seu período de análise. A variação de hemócitos/ $\mu \mathrm{L}$ em relação às doses dos sais de zinco nos diferentes tempos analisados são apresentadas nas figuras (Fig. 1 e Fig. 2).

Figura 1. Relação de Hemócitos $/ \mu \mathrm{L}$ e diferentes doses de $\mathrm{ZnSO}_{4} \mathrm{em} \mathrm{g} \mathrm{L}^{-1}$ nos tempos de $24 \mathrm{e} 48$ horas de exposição às doses.

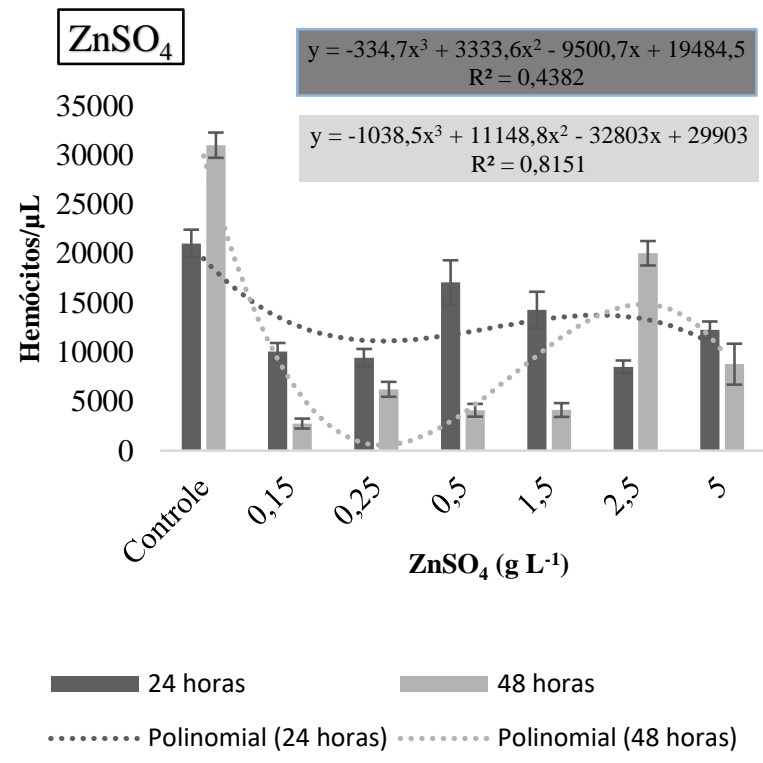

Figura 2. Relação de Hemócitos/ $\mu \mathrm{L}$ e diferentes doses de $\mathrm{ZnCl}_{2} \mathrm{em} \mathrm{g} \mathrm{L}^{-1}$ nos tempos de $24 \mathrm{e} 48$ horas de exposição às doses.

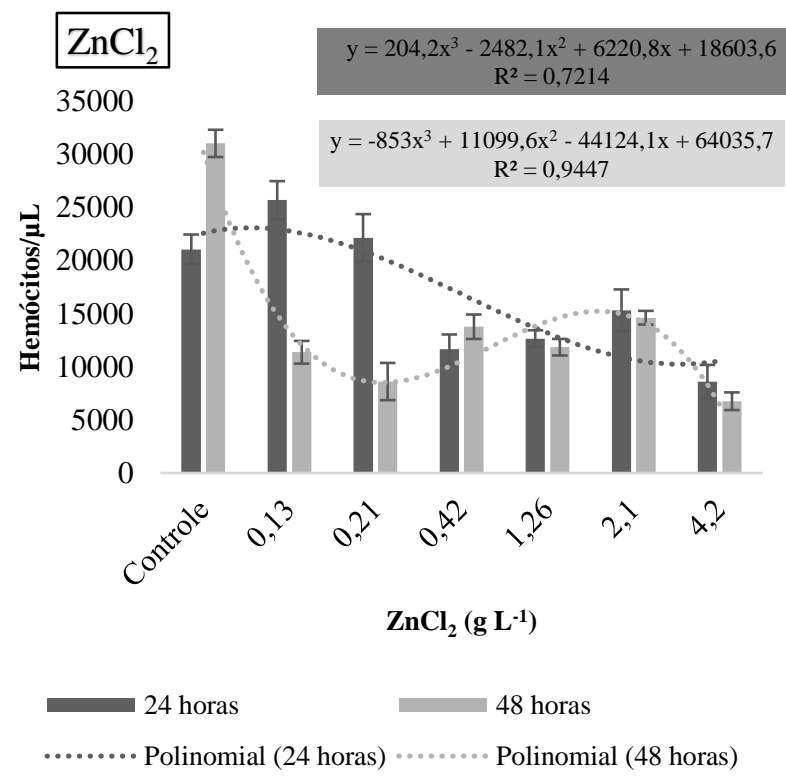

De maneira geral, exposição a diferentes concentrações de $\mathrm{ZnSO}_{4}$ implicaram diretamente na diminuição de hemócitos de A. sexdens, comportamento não verificado apenas na concentração de 2,5 $\mathrm{g} \mathrm{L}^{-1}$, em que, é possível notar um aumento na produção de hemócitos. Comparado ao grupo controle, nota-se uma inclinação decrescente nos diferentes tempos (Fig. 1). No entanto, só houve uma diminuição significativa de hemócitos num período de 48 horas. Esses resultados indicam que o tempo de exposição ao composto está diretamente ligado com o decaimento da imunidade. A dose de $\mathrm{ZnSO}_{4}$ que mais afetou a imunidade das formigas no período de 48 horas foi a de $0,15 \mathrm{~g} \mathrm{~L}^{-1}$, quando a quantidade média de 2.750 hemócitos/ $\mu \mathrm{L}$.

Em relação ao controle, foi possível observar redução significativa em ambos os tempos analisados no decorrer do experimento (Fig. 2). Para o tempo de 24 horas, as concentrações $0,13 \mathrm{~g} \mathrm{~L}^{-1}$ e $0,21 \mathrm{~g} \mathrm{~L}^{-1} \mathrm{de}$ cloreto de zinco provocam um superprodução de hemócitos em relação ao grupo controle. Porém, quando tais concentrações mantiveram-se por mais tempo nas operárias (após 48 horas), a produção de hemócitos diminuiu em relação ao do grupo controle, podendo-se então sugerir que a exposição a diferentes doses de $\mathrm{ZnCl}_{2}$ comportam-se de forma semelhante ao $\mathrm{ZnSO}_{4}$, isto é, o tempo de exposição a esses compostos levam a uma queda significativa na produção de hemócitos. A maior concentração de zinco na forma de cloreto $\left(4,2 \mathrm{~g} \mathrm{~L}^{-1}\right)$ afetou mais significativamente a imunidade das operárias em ambos os tempos com 8.600 e 6.750 hemócitos/ $\mu \mathrm{L}$ em 24 e 48 horas respectivamente.

Pipe et al. (1999) ressaltam que, embora o aumento no número de hemócitos seja uma resposta comum ao estresse ambiental, ele não pode ser visto como uma regra. Segundo Pipe e Coles (1995), a 
diminuição do número total de hemócitos sob condições de estresse pode ser consequência de lise celular, recrutamento reduzido ou movimentação das células da circulação para os tecidos.

Supõem-se que a variação no número de hemócitos é regulada pela liberação de células do tecido hematopoiético complementado pela migração celular entre os diversos tecidos do organismo, eles são constantemente produzidos para substituir aqueles que morreram ou que foram metabolicamente danificados (PEREZ e FONTANETTI, 2011). No entanto, a taxa em que esse processo ocorre pode ser alterada pela influência de vários fatores ambientais (JOHANSSON et al. 2000; JIRAVANICHPAISAL et al., 2006).

As taxas de encapsulação, medida através do valor cinzento de cada implante em ambas as formas de sais de zinco nos tempos indicados (Fig. 3 e Fig. 4), não apresentaram diferenças significativas entre os grupos ( $p \leq 0,05)$. É possível observar uma tendência de aumento da taxa de encapsulação em níveis moderados de concentração de sais de zinco, fato esse observado por Sorvari (2007), em que formigas da espécie Formica aquilona translocadas e próximas a zona de contaminação industrial por metais pesados apresentaram comportamento semelhante.

Figura 3: Taxa de encapsulação (valor de escuridão do implante) de operárias de Atta sexdens em relação a diferentes concentrações de $\mathrm{ZnSO}_{4} \mathrm{em} \mathrm{g} \mathrm{L}^{-1}$ nos tempos de $24 \mathrm{e} 48$ horas de exposição às concentrações (Scott-Knott p < 0,05).

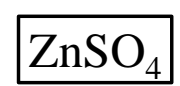

80

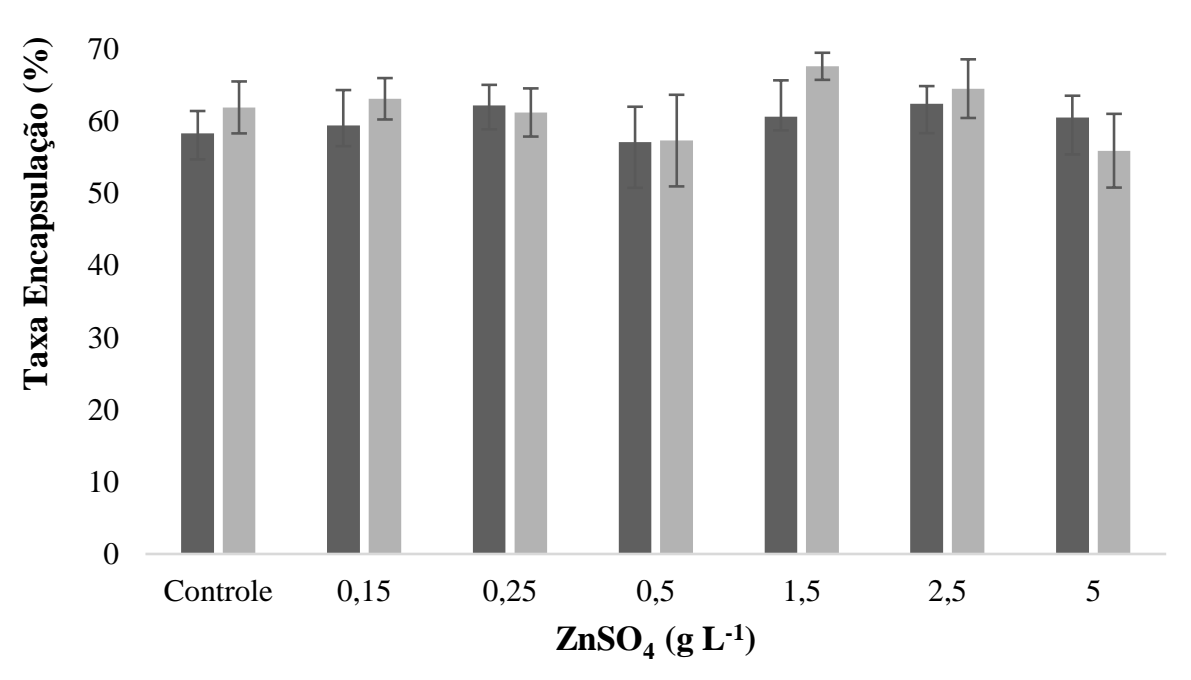

- 24 horas $\quad 48$ horas 
Figura 4: Taxa de encapsulação (valor de escuridão do implante) de operárias de Atta sexdens em relação a diferentes concentrações de $\mathrm{ZnCl}_{2}$ em $\mathrm{g} \mathrm{L}^{-1}$ nos tempos de $24 \mathrm{e} 48$ horas de exposição às concentrações (Scott-Knott $\mathrm{p}<0,05)$.

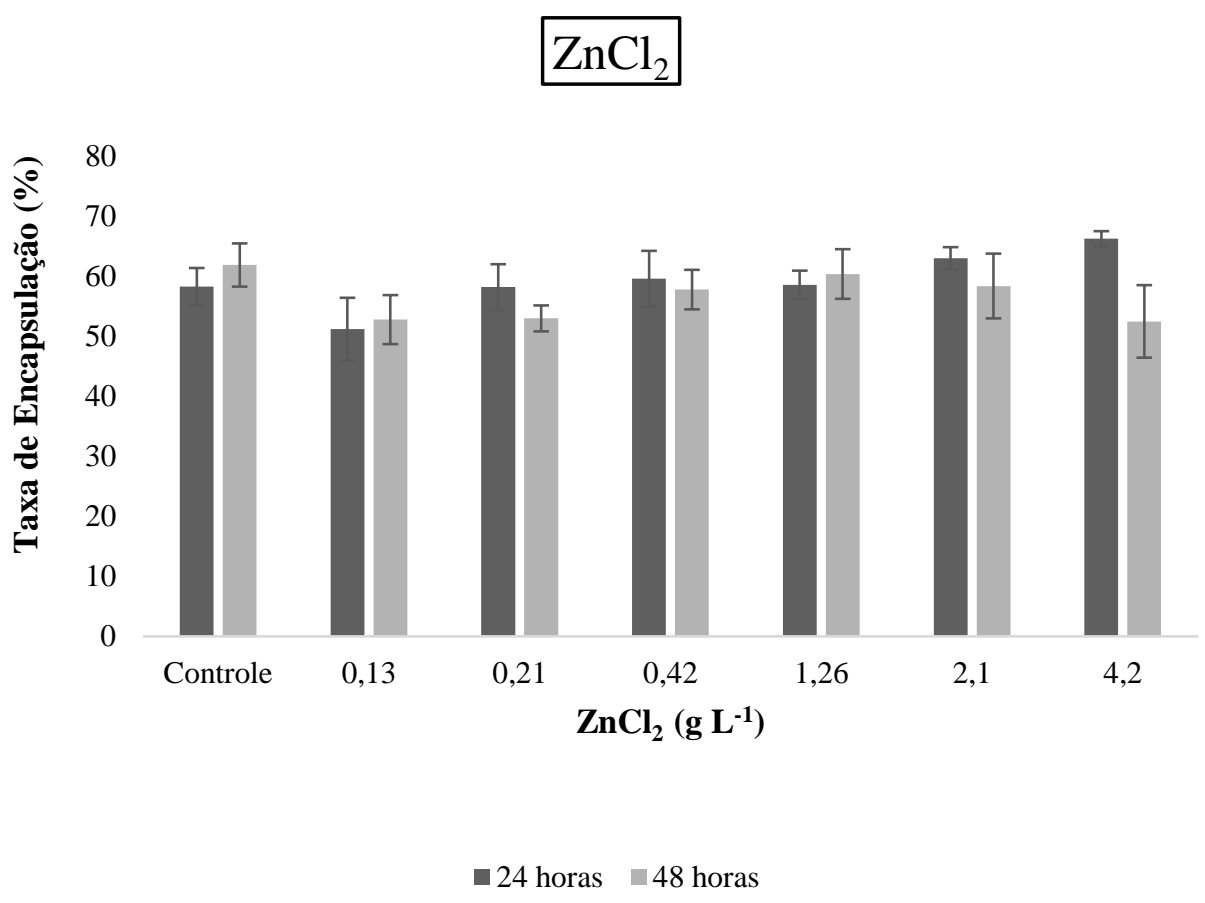

É possível observar a partir dos dados de taxa de encapsulação e quantificação total de hemócitos/ $\mu \mathrm{L}$ no tempo de 24 horas, uma relação inversamente proporcional em $\mathrm{ZnCl}_{2}$, indicando uma correlação significativa $(\mathrm{p}<0,05)$ de Spearman de $-0,828571$. Nesse tempo, a concentração de cloreto de zinco que provocou maior taxa de encapsulação foi a de $4,2 \mathrm{~g} \mathrm{~L}^{-}$ ${ }^{1}$ com $92,16 \%$, sendo também a que causou a menor quantidade de hemócitos $\mu \mathrm{L}$ com 8.600 hemócitos $/ \mu \mathrm{L}$. O contrário foi observado na concentração de $0,13 \mathrm{~g}$ $\mathrm{L}^{-1}$, em que a menor taxa de encapsulação de $77,65 \%$ foi a que proporcionou maior aumento de hemócitos (25.650 hemócitos $/ \mu \mathrm{L}$ ).

Fageria (2000) destaca dosagens adequadas de Zn baseados em $90 \%$ da produção relativa de matéria seca como parâmetro em solos do Cerrado, em que utiliza 10, 1, 3, 2 e $1 \mathrm{mg}$ de $\mathrm{Zn} \mathrm{kg}^{-1}$ de solo para as culturas de arroz, feijão, milho, soja e trigo respectivamente. Tendo em vista os benefícios em que baixas concentrações de $\mathrm{Zn}$ trazem a certas culturas, elas podem ser usadas também como aliadas para auxiliar no controle de formigas-cortadeiras da espécie A. sexdens, numa estratégia de imunossupressão desses insetos que os tornem mais suscetíveis a patógenos de oportunistas de ocorrência em seu ambiente.

\section{CONCLUSÃO}

O sulfato de zinco apresentou-se mais eficiente na redução dos hemócitos de operárias da espécie A. sexdens, durante longo período de tempo de exposição ao composto em relação ao cloreto de zinco, pois menores concentrações foram capazes de reduzir mais significativamente a imunidade desses insetos em relação às maiores concentrações. Porém, o cloreto de zinco apresentou interação significativa em ambos os tempos. 
Devido à baixa biodisponibilidade de $\mathrm{Zn}$ na região do Cerrado, é possível concluir que a aplicação de pequenas concentrações desse micronutriente na forma de sulfato poderia ser benéfico para a cultura de Eucalyptus e poderia afetar diretamente o sistema imune de formigas auxiliando, indiretamente, em seu controle.

Mais estudos devem ser realizados visando uma melhor compreensão do comportamento imune desses insetos objetivando formas de controlar formigas-cortadeiras consideradas nocivas ao sistema agrossilvipastoril.

\section{AGRADECIMENTOS}

Os autores agradecem ao Conselho Nacional de Tecnologia e Desenvolvimento Científico (CNPq) pelo apoio financeiro. À Universidade Federal do Tocantins (UFT) pelo apoio institucional. À Doutora Yadira Ibargüen-Vargas, Université d'Orléans, França, pela revisão do resumo em espanhol.

Todos os autores declararam não haver qualquer potencial conflito de interesses referente a este artigo.

\section{REFERÊNCIAS}

COUCEIRO, J. C.; MARCELINO, W. L.; AMARAL, K. D.; GRANDA, L. C.; de SOUZA, D. J.; DELLA LUCIA, T. M. C. Effects of entomopathogenic fungi on the mortality and immune system of the leaf-cutting ant Acromyrmex subterraneus subterraneus. Entomol. Exp. App. v. 161, n. 2, p. 152-159, 2016.

DELLA LUCIA, T. M.; GANDRA, L. C.; GUEDES, R. N. Managing leaf-cutting ants: peculiarities, trends and challenges. Pest. Manag. Sci. v. 70, n. 1, p. 14-23, 2014.

DELLA LUCIA, T. M. C. Formigas cortadeiras: da bioecologia ao manejo. Viçosa, Editora UFV, 419 p., 2011.

de SOUZA, D.J.; LENOIR, A.; KASUYA, M. C. M.; RIBEIRO, M. M. R.; DEVERS, S.; COUCEIRO, J. C.; DELLA LUCIA, T. M. C. Ectosymbionts and immunity in the leaf-cutting ant Acromyrmex subterraneus subterraneus. Brain. Behav. Immun. v. 28, p. 182-187, 2013.

FAGERIA, N.K. Níveis adequados e tóxicos de zinco na produção de arroz, feijão, milho, soja e trigo em solo de cerrado. Rev. Bras. Eng. Agríc. Ambient. v.4, n.3, p.390-395, 2000.

FERREIRA, D. F. Sisvar: A computer statistical analysis system. Ciênc. Agrotec. v. 35, n. 6, p. 10391042, 2011.

GALRÃO, E.Z. Métodos de correção da deficiência de zinco para o cultivo do milho num Latossolo Vermelho-Escuro argiloso sob cerrado. Rev. Bras. Ciênc. Solo. v.18, n.2, p.229-233, 1994.

JIRAVANICHPAISAL, P.; LEE, B. L.; SÖDERHÄLL, K. Cell-mediated immunity in arthropods: hematopoiesis, coagulation, melanization and opsonization. Immunobiology. v. 211, n.4, p. 213-236, 2006.

JOHANSSON, M. W.; KEYSER, P.; SRITUNYALUCKSANA, K.; SÖDERHÄLL, K. Crustacean haemocytes and haematopoiesis. Aquaculture. v. 191, p. 45-52, 2000.

LEONARD, C.; SÖDERHÄLL, K. \& RATCLIFFE, N. A. Studies on prophenoloxidase and protease activity of Blaberus craniifer haemocytes. Insect Biochem. v.15, n.6, p.803-810, 1985.

MARSCHNER, H. Mineral Nutrition of Higher Plants. $2^{\text {a }}$ ed., Academic Press, 889 p., 1995.

PEREZ, D. G.; FONTANETTI, C. S. Hemocitical responses to environmental stress in invertebrates: a review. Environ. Monit. Assess. v. 177, n. 1-4, p. 437-447, 2011.

PIPE, R. K.; COLES, J. A. Environmental contaminants influencing immune function in marine bivalve molluscs. Fish Shellfish Immun. v. 5, n. 8, p. 581-595, 1995.

PIPE, R. K.; COLES, J. A.; CARISSAN, F. M. M.; RAMANATHAN, K. Copper induced immunomodulation in the marine mussel, Mytilus edulis. Aquat. Toxicol. v. 46, n. 1, p. 43-54, 1999.

QAMAR A. Haemocytes of Dysdercus cingulatus (Hemiptera Pyrrhocorirae) affected with DDT, Cythion and Furadan. M. Phil. Dissertation Aligarh Muslim University Aligarh India. 1990.

QAMAR A, JAMAL K. Differential haemocyte counts of 5th instar nymphs and adults of Dysdercus cingulatus Fabr. (Hemiptera: Pyrrhocoridae) treated 
with acephate, an organophosphorus insecticide. Biol. Med. v.1, n. 2, p. 116-121, 2009.

RATCLIFFE, N. A.; ROWLEY, A. F. Role of haemocytes in defense against biological agents. In: A. GUPTA, editor. Insect haemocytes: development, forms, functions and techniques. Cambridge: Cambridge University Press. p. 331-414, 1979.

RATCLIFFE, N. A.; ROWLEY, A. F.; FITZGERALD. S. W.; RHODES, C. P. Invertebrate Immunity: Basic Concepts and Recent Advances. Int. Rev. Cytol. v. 97, p. 183-350, 1985.

RIBEIRO, C.; BREHÉLIN, M. Insect haemocytes: What type of cell is that? J. Insect Physiol. v. 52, n. 5 p. 417-429, 2006.

RODRIGUES, F. A. V.; de BARROS, N. F.; NEVES, J. C. L.; ALVAREZ, V. H. V.; NOVAIS, R. F. Disponibilidade de zinco para mudas de eucalipto em solos de Cerrado. Rev. Bras. Ciênc. Solo. v. 36, n. 4, p. 1249-1258, 2012.

SIDDIQUI, M. I.; AL-KHALIFA, M. S. Review of haemocyte count, response to chemicals, phagocytosis, encapsulation and metamorphosis in insects. Ital. J. Zool. v. 81, n.1, p. 2-15, 2014.
SILVA, D. G. Efeito do fungo Trichoderma harzianum e do zinco em colônias de Atta sexdens. Dissertação apresentada ao Programa de Pósgraduação em Ciências Florestais e Ambientais UFT. Gurupi, p. 69, 2016.

SORVARI, J.; HAKKARAINEN, H.; RANTALA, M. $\mathrm{J}$. Immune defense of ants is associated with changes in habitat characteristics. Environ. Entomol. v. 37, n. 1. p. 51-56, 2008.

SORVARI, J.; RANTALA, L. M.; RANTALA, M. J.; TAPIO, E. Heavy metal pollution disturbs immune response in wild ant populations. Environ. Pollut. v. 145, n. 1, p. 324-328, 2007.

VENDRAME, P. R. S.; BRITO, O. R.; QUANTIN, C. BECQUER, T. Disponibilidade de cobre, ferro, manganês e zinco em solos sob pastagens na Região do Cerrado. Pesquisa Agropecuária Brasileira. v. 426, p. 859-864, 2007.

WASHBURN, J. O.; KIRKPATRICK, B. A.; VOLKMAN, L. E. Insect protection against viruses. Nature. v. 383, p. 767, 1996.

WOOD, W.; JACINTO, A. Drosophila melanogaster embryonic haemocytes: masters of multitasking. Nat. Rev. Mol. Cell. Biol. Molecular Cell Biology. v. 8, n. 7, p. 542-551, 2007. 